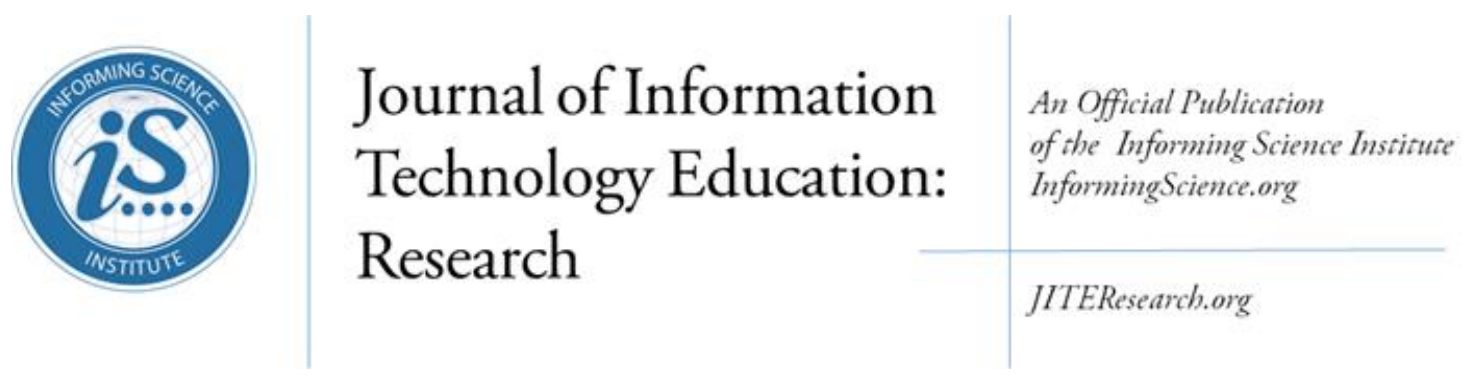

Volume 19, 2020

\title{
A Self-assessment Approach to Adolescents' CYBERETHICS EDUCATION
}

\author{
Wing Shui $\mathrm{Ng}^{*}$ \\ * Corresponding author
}

The Open University of Hong Kong,

wsng@,ouhk.edu.hk Hong Kong

\section{ABSTRACT}

Aim/Purpose

Teachers usually educate students' cyberethics using debate, case-based discussion, and role-playing instructional methods in a face-to-face setting. With the presence of teacher and peers, students may not be willing to share their true attitudes, and it may affect the effectiveness of the teaching methods. To tackle the challenge, the author applied a teaching method with a core component of a pressure-free self-assessment approach to improving adolescents' cyberethics education. This study aimed to explore the impact of the self-assessment method on students' self-knowledge and self-awareness of cyberethics.

Background Since people usually use their own devices in an individual environment to participate in online activities, going online can be regarded as a private act. The behaviours of youngsters in the online environment may be different from that in the classroom when they are engaged in a face-to-face discussion, especially as they are not required to use their real names to go online. Research has suggested that youngsters have a higher inclination to misbehave online. Together with the fact that they are regular Internet users, and they are overrepresented online, there is an urgent need to foster ethical online behaviour in adolescents.

Methodology

A group of 28 students of age about 14 participated in this study. They were studying in secondary level 3 of a government-subsidised secondary school. All of them were required to take an information technology course in their formal curriculum. The researcher applied a framework of adolescents' cyberethics education to nurture the students with appropriate cyberethics. It includes four dimensions, namely information security, privacy, intellectual property and netiquette. In the first phase of the teaching method, the students received a lecture on cyberethics to obtain related knowledge. In the second phase, the students were engaged in a self-assessment exercise on cyberethics. Data were collected using a knowledge test, a questionnaire, and the self-assessment exercise.

Accepting Editor Man Fung (Kelvin) LO | Received: May 13, 2020 | Revised: August 19, 2020 | Accepted: August 24, 2020.

Cite as: Ng. W. S. (2020). A self-assessment approach to adolescents' cyberethics education. Journal of Information Technology Education: Research, 19, 555-570. https://doi.org/10.28945/4623

(CC BY-NC 4.0) This article is licensed to you under a Creative Commons Attribution-NonCommercial 4.0 International License. When you copy and redistribute this paper in full or in part, you need to provide proper attribution to it to ensure that others can later locate this work (and to ensure that others do not accuse you of plagiarism). You may (and we encourage you to) adapt, remix, transform, and build upon the material for any non-commercial purposes. This license does not permit you to use this material for commercial purposes. 
Contribution This paper highlights the challenge arisen from the face-to-face setting of commonly used instructional methods of cyberethics education, such as role-playing and debate. This study suggested a self-assessment teaching method with the rationales underpinned by theories in the area of social psychology. This paper provides detailed elaboration on the instructional method. The author also suggested a framework of adolescents' cyberethics education.

Findings The students considered the self-assessment exercise allowed them to reflect on their attitudes on cyberethics. It thereby enhanced their self-knowledge on cyberethics. They also expressed that the method was more effective for self-reflection compared with commonly used instructional methods. Moreover, importantly, they stated that they would be more aware of cyberethics in their future online activities.

Recommendations Teachers are advised to use a self-assessment exercise together with commonly for Practitioners used instructional methods, such as case-based discussion, debate, and roleplaying, in their future practices of cyberethics education.

Recommendations for Researchers

Researchers could consider youngsters' cognitive and psychological development, and social and emotional factors to improve adolescents' cyberethics education.

Impact on Society It is anticipated that youngsters would have a higher level of awareness to uphold information security, protect privacy, respect intellectual property and maintain appropriate netiquette. They could then demonstrate more appropriate behaviours when they go online after receiving cyberethics education using the approach elaborated in this paper.

Future Research It is valuable to explore how different factors in cognitive, psychological, social, and emotional domains affect youngsters' online behaviours. Future research may also design effective instructional methods to improve adolescents' cyberethics education.

Keywords cyberethics, moral education, self-presentation, self-knowledge, self-awareness, self-assessment

\section{INTRODUCTION}

With the advancement of technology, the Internet has expanded drastically over the last couple of decades. The Internet provides a cyberspace that enables people to exchange information and perform different online activities. Notwithstanding that the Internet brings many benefits to our daily life, people interacting in cyberspace is actually in the nature of social behaviours, and the issue of cyberethics has come to our concerns. One particularly problematic group is adolescents. These young people often kick against rules and restrictions as they search to establish their own identity (Gilmore \& Meersand, 2015). This behavioural pattern makes adolescents difficult to develop appropriate attitudes on cyberethics. Adolescents have been found with high frequency to engage in the invasion of privacy, theft of confidential information, violation of intellectual property rights and misbehaviour of cyberbullying (Ang et al., 2014; Gunter et al., 2010; Hu et al., 2013; Kowalski \& Limber, 2007; Park et al., 2014; Raskauskas \& Stoltz, 2007). It is particularly important to address the issue of adolescent cyberethics as a very high proportion of their age group are regular Internet users, and they are overrepresented online (Census and Statistics Department HKSAR, 2020; Clement, 2019). 
One of the best solutions to address the issue of cyberethics amongst digital citizens is through the values of education (Onyancha, 2015; Sharma et al., 2015; Whittier, 2013). A number of studies have focused on education to improve behaviour on the Internet (see, for example, Dhir et al., 2016; Hur et al., 2009; Ncube \& Dube, 2016). A range of instructional methods such as case-based discussion, debate and role-playing has been used to engage students in critical dialogues on ethical issues between learners (Dow et al., 2015; Hur et al., 2009; Lin, 2016; Liu \& Yang, 2012). The purpose of these learning activities was to engage students in multiple discussions on ethical dilemmas in an open setting with the hope of developing appropriate attitudes and ethical behaviour on the Internet. However, going online is a very personal and private activity. The open setting in the implementation of ethics courses is entirely different from the personal and private physical setting of carrying out online activities, especially that adolescents are not necessary to use their real names when going online. Adolescents in the private physical environment may not behave in the same way as when in a class where their behaviour is open to public criticism. Consequently, related instructional methods implemented in an open setting may not produce the desired change in online behaviour.

Research in the field of social psychology has found that people are inclined to deliberately express a self-presentation in a public setting (Schlenker, 1975). Self-presentation refers to deliberate efforts to act in ways that create a particular impression of the self to obtain a desired outcome (Taylor et al., 2006). Adolescents are still developing their identity and may have difficulties in understanding who they are themselves (Gilmore \& Meersand, 2015). Consequently, they may self-present to appear to align themselves with publicly accepted ethical decisions in an open setting to meet the expectations of peers, teachers and parents. For example, in the study by Juvonen and Murdock (1995), the fourth- and sixth-grade students desired to create a self-presentation to portray themselves as effortful to teachers and peers. Therefore, the behaviours exhibited by students in a classroom learning about cyberethics may not reflect students' underlying values or attitudes nor how they will behave online. It is questionable whether commonly used teaching methods for nurturing cyberethics, such as open discussion and debate, will encourage students to freely express their attitudes to ethical issues, and thereby help them to change their unethical behaviour. Since online activities are usually conducted in an individual physical environment, the level of self-knowledge and self-awareness becomes a critical factor affecting adolescents' decisions when they encounter ethical issues (Diener, 1976). Self-knowledge refers to a set of information or beliefs about oneself, while self-awareness refers to the attention directed to the self (Baumeister \& Bushman, 2016). To enhance self-knowledge and self-awareness, adolescents are required to undergo a self-reflection process. Research has suggested that a self-assessment exercise helps students engage in a self-reflection process for personal growth (Desjarlais \& Smith, 2011; Leise, 2007). This study aimed to foster adolescents' cyberethics by enhancing their self-knowledge and self-awareness on related ethical dimensions, using a self-assessment approach, to improve their online behaviours. The researcher attempted to investigate the research question 'What is the impact of a pressure-free self-assessment method on students' selfknowledge and self-awareness of cyberethics?"

In the next section, the issue of adolescent online behaviour and potential solutions is explored. This is followed by the methodology of this study. The results section provides the outcomes of the analysis, and this is followed by a discussion of the results and the conclusion.

\section{LITERATURE REVIEW}

An overview of adolescents' unsatisfactory online behaviours and the urgent need to deal with adolescents' cyberethics are explored in this section. A framework of adolescents' cyberethics is then proposed. The researcher then highlighted the inadequacy of commonly used methods that adopt an open setting in ethics education. To tackle the deficiency, the researcher proposed to enhance adolescents' self-knowledge and self-awareness on cyberethics using a pressure-free self-assessment method. 


\section{ADOLESCENTS'ONLINE BEHAVIOURS}

In the literature, there is no agreement on the age range of adolescence. For example, adolescence was defined as the age range of 12 to 17 years in the worldwide survey of Programme for International Student Assessment (PISA) conducted by Organisation for Economic Co-operation and Development (OECD, 2014). Based on the United Nations Children's Fund (UNICEF, 2020) and the World Health Organization (WHO, 2020), adolescence refers to the age ranged from 10 to 19. This study defines adolescence as ranging from 10 to 19, covering adolescents from the upper primary level to senior secondary level of education. Halpern-Felsher (2012) described adolescence is a time of great and rapid cognitive, psychological, social, emotional, and physical change and is also often a time of engagement in risky behaviours. Adolescents take more risks than children or adults (Steinberg, 2007). Adolescence is characterized by the desire for autonomy in making decisions. However, adolescents may lack the psychological traits required to make and act upon mature decisions consistently. Their decisions are often impulsive rather than planned. This may be due to their perception that there is a low likelihood of experiencing negative consequences, that they are invulnerable to harm and their poorly developed decision-making skills (Halpern-Felsher, 2012). In a study by Cauffman and Steinberg (2000), 1,015 participants ranging in age from 12 to 48, of mixed gender, socioeconomic status and ethnicity, were invited to complete a questionnaire to evaluate their maturity in decision-making. It was found that antisocial decision-making was significantly affected by age, and it was negatively correlated with levels of psychosocial maturity. Once the developmental changes of adolescence are complete in the age of around 19, the maturity of judgment becomes stabilized. When adolescents go online, they may struggle with whether to download free but copyright-protected materials, such as pirated software or music. They may also be enticed to copy web contents directly to their homework but ignore to cite the reference. It incurs the risk of being charged with committing plagiarism and cheating (Varlan \& Tomozei, 2018). It suggests that helping adolescents to make appropriate decisions when facing dilemmas on cyberethics is a critical issue.

According to a recent statistical report (Census and Statistics Department, 2020), 100\% and 99.9\% of citizens in the age range of $10-14$ and $15-24$ respectively were regular Internet users. In a global statistical report, the number of Internet users aged 16-24 was found to be much higher than other age groups (Clement, 2019). While a large proportion of adolescents are regular Internet users, their online behaviours are causes for concern. They incline to demonstrate certain antinormative behaviours, which are the actions against the prescriptive norms of the society (Vaz \& Kanekar, 1992). For example, students frequently engaged in the invasion of privacy, theft of confidential information, and violation of intellectual property rights (Gunter et al., 2010; Hu et al., 2013). In addition, a study conducted by The Hong Kong Institute of Education (2007) mentioned that primary and secondary school students were less concerned about the improperness of sending or forwarding unnecessary emails or messages. Secondary school students even showed less concern about using pirated software. More importantly, cyberbullying has become a new type of bullying among adolescents, and it has been an issue of considerable concern (Ang et al., 2014; Kowalski \& Limber, 2007; Park et al., 2014; Raskauskas \& Stoltz, 2007). These findings suggest an urgent need to foster ethical behaviour in adolescents.

\section{FRAMEWORKOF ADOLESCENTS'CYBERETHICS}

In the domain of ethics, cyberethics comes under the broader area of information ethics (Capurro, 2005; Spinello \& Tavani, 2004). Information ethics covers issues such as social responsibility, citizenship, global information justice, freedom of speech, copyright and privacy in the areas of the Internet, computer science, library and information science, medical sciences, mass media and business (Capurro, 2005; Shiri, 2016). The scope of cyberethics is confined to the ethical issues in a computer network environment. Spinello and Tavani (2004) defined cyberethics as "the field of applied ethics that examines moral, legal, and social issues in the development and use of cybertechnology" (p. 1). They further clarified that "cybertechnology refers to a broad spectrum of technologies that range 
from stand-alone computers to the cluster of networked computing, information, and communication technologies" (p. 1).

To explore different dimensions of cyberethics for educating adolescents, the framework of information ethics developed by Mason (1986) which comprises privacy, accuracy, property and accessibility (PAPA) can be regarded as a useful reference since it has been adopted in many studies (Harncharnchai \& Inplao, 2015; Masrom et al., 2013; McBride, 2014; Ming et al., 2015; Woodward, 2010). According to Mason (1986), the dimension of privacy addresses the right to keep or reveal information of an individual or a particular association. The dimension of accuracy concerns the fidelity and integrity of information. Regarding the dimension of property, it emphasizes the ownership of information, including intellectual property rights. The last dimension of the framework is accessibility. It refers to the availability of information for an individual or an organization to obtain.

However, it should be noted that Mason's (1986) framework of information ethics was developed in the very early stages of Internet development. With the rapid development of the Internet, information security has become an important issue and governments or organizations are inevitably required to initiate policies, procedures and standards to tackle the issue (Layton, 2016; Peltier, 2016). Adolescents are considered more vulnerable to the threat of information security since they are still developing their logical thinking skills and knowledge of the society. The dimensions of accuracy and accessibility in Mason's (1986) framework that deal with integrity and availability of information come under the broader scope of information security (Von Solms \& Van Niekerk, 2013). Therefore, it is considered appropriate to combine the dimensions of accuracy and accessibility and to explore information security as a whole to reflect technology advancement. On the other hand, adolescents' aggressive behaviour in cyberspace in the form of cyberbullying has become a critical issue that is raising peoples' concern (Kowalski \& Limber, 2007; Raskauskas \& Stoltz, 2007). To deal with aggressive behaviours in cyberspace, researchers consistently suggest educating adolescents' appropriate netiquette (Ang et al., 2014; Lazuras et al., 2012; Park et al., 2014). Netiquette, known as Internet etiquette, refers to a set of rules and guidelines for appropriately using the Internet (Shea, 1994). It has been recognized with the potential to reduce antisocial behaviour in online interaction (Ang, 2015). For example, in the large scale study by Kumazaki et al. (2011), over 4000 students were invited to express their opinions on the relationship between netiquette and cyberethics. Results suggested that proper netiquette enhanced the ethical judgement of adolescents, and it is a critical factor to prevent cyberbullying. In line with this consideration, netiquette is also considered as an important dimension to nurture adolescents' cyberethics. To sum up, the framework of adolescents' cyberethics education which includes information security, privacy, intellectual property and netiquette was used in this study (Figure 1).

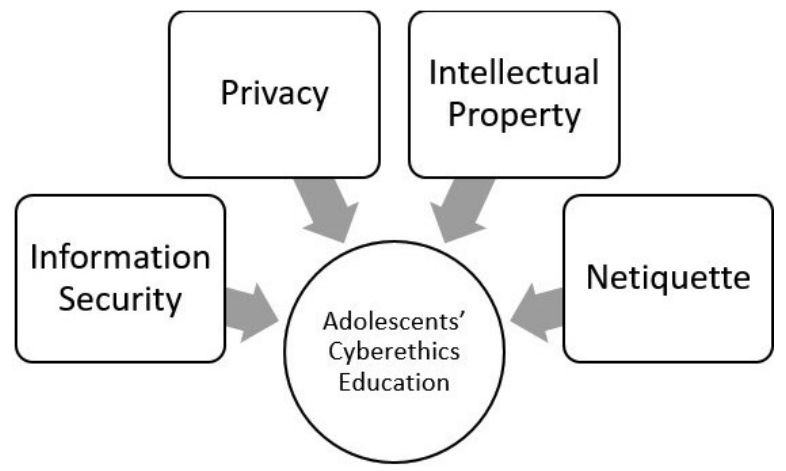

Figure 1: Framework of adolescents' cyberethics education

\section{INADEQUACY OF COMMON CYBERETHICS INSTRUCTIONAL METHODS}

To nurture students with appropriate ethical values and attitudes, teachers frequently used the method of case-based group discussion of ethical dilemmas. For example, in the study by Lin (2016), 
case-based instruction was used to engage students in open discussions on ethical dilemmas. The teacher then used the values clarification method to educate students. In another study by Dow and colleagues (2015), students were arranged in groups to discuss assigned cases. Students were required to apply a decision-making model and to create a presentation. In the study by Tatsumi and colleagues (2013), students were arranged to discuss topics of dilemmas related to network communication or copyright issues. This study suggested that students' motivation for learning improved significantly. Similar to the case-based discussion, researchers also applied other instructional methods to engage students in critical dialogues. Hur (2009) and his colleagues suggested a cooperative narration approach. Students were encouraged to talk about their own experiences of moral judgment to each other related to their daily Internet activities. They were then instructed to exchange feedback. Moreover, Liu and Yang (2012) suggested that debates and role-playing are frequently used methods. It provides an opportunity for learners to engage in dialogue.

It is undeniable that related instructional methods, such as case-based group discussion on ethical dilemmas, cooperative narration, debates and role-playing, are able to have a positive impact on adolescents' cyberethics (Dow et al., 2015; Hur et al., 2009; Lin, 2016; Tatsumi et al., 2013). As suggested by Kohlberg and Hersh (1977), in their elaboration of cognitive moral development theory, classroom ethical discussion is an approach to stimulate moral development. It engages students to face moral conflicts and to think about the underlying reasoning. However, students in an open classroom setting, being observed by peers and teachers may behave very differently when they go online in a private physical environment, especially if they are not using their real name or identity.

Research in the field of social psychology has found that people are inclined to deliberately express a self-presentation in a public setting to create a good impression or to obtain the desired outcome (Schlenker, 1975; Taylor et al., 2006). Individuals are motivated to maximize social approval and minimize social disapproval (Goffman, 2010) and generally prefer favourable rather than unfavourable evaluation (Jones, 1973). Schlenker (1975) stressed that "individuals are more generous with their self-attribution, less critical of themselves, and more desirous of receiving favourable interpersonal evaluations when their future behaviour and past failures are not open to public scrutiny" (p. 1032). Besides, individuals incline to be more confident in themselves irrespective of their personal expectations of actual performance under anonymous conditions where future events posed no threat to self-presentations (Schlenker, 1975). These tendencies are more likely to come to play in an open classroom. Adolescents may express a self-presentation to obtain a favourable evaluation from their

peers and teacher, important to them as they are still in the process of establishing their identity (Silva et al., 2016). If students adopt a self-presentation in the classroom, such as one of conformity, they are unlikely to have their true views challenged and therefore unlikely to change their attitudes and behaviours on cyberethics. Consequently, it appears that the instruction methods which engage students in an open setting are not effective enough to nurture adolescents' cyberethics.

\section{EFFECTS OF SELF-KNOWLEDGE AND SELF-AWARENESS ON ANTINORMATIVE BEHAVIOUR}

Since online activities are usually conducted in an individual physical environment, to improve students' self-knowledge and self-awareness is considered as a possible method to remedy the inadequacy of commonly used instructional methods. Self-knowledge refers to a set of information or beliefs about oneself (Baumeister \& Bushman, 2016). It includes the knowledge of affective states, motivational states and action orientations of the self. It also covers "the self-knowledge of preferences and values, of goals and motives, and of rules and strategies for regulating and controlling behaviour" (Markus, 1983, p. 544). As suggested by Markus (1983), self-knowledge plays a significant role in determining the nature, direction, and intensity of the behaviour. It has a strong connection with the future behaviour of an individual. The behaviour of the individual is closely related to the individual's own needs, desires, goals, and expectations. Self-knowledge is therefore critical in mediating behaviour, and it serves to frame behaviour, to guide it, and to direct its course. 
Self-awareness is closely related to self-knowledge. Self-awareness refers to the attention directed to the self (Baumeister \& Bushman, 2016). The level of self-awareness improves with a higher level of self-knowledge. Baumeister and Bushman (2016) suggested that self-awareness is part of the mechanism by which people can bring themselves to consider what other people want and expect. Selfawareness, therefore, makes people more adapted to societal standards and act in a more socially desirable manner. Increased self-awareness can also make people act more consistently with their attitudes in relation to many different issues. Similar arguments were emphasized by Duval and Wicklund (1972), who found that a self-aware person will be more likely to act in a normative manner than a non-self-aware person. Diener (1976) also reported that self-awareness serves to inhibit unrestrained, impulsive behaviour. Therefore, self-awareness is generally able to make people more aware of positive, desirable standards and make them try harder to behave positively. As suggested by the literature, adolescents, with higher self-knowledge and self-awareness on cyberethics, are therefore believed to behave more ethically when they face ethical situations during online.

\section{EFFECTS OF SELF-ASSESSMENT ON BEHAVIOUR}

To enhance self-knowledge and self-awareness, the researcher engaged students in a self-assessment process in this study. Self-assessment refers to the involvement of individuals in making judgments about their own performance (Boud \& Falchikov, 1989). The purposes are to allow students to identify their strengths and areas of improvement (Desjarlais \& Smith, 2013). As stated by Desjarlais and Smith (2013), self-assessment is usually externally motivated by mentors. Students are encouraged to be proactive to carry out self-assessment. Often, some performance criteria are provided to guide the self-assessment process. Students, in self-assessment, are engaged in a forward-looking convergent thinking process that leads to some improved performance. During the process of self-assessment, students usually trigger a reflection process to review their past experiences $(\mathrm{Ng}, 2020)$. Leise (2007) claimed that both novices and experts could increase growth in the process of learning through cycles of assessment and reflection. Reflection is "a process that involves playing back a period of time related to previous valued experiences in search of significant discoveries or insights about oneself, one's behaviours, one's values, or knowledge gained" (Desjarlais \& Smith, 2013, p. 3). Amulya (2004) highlighted that the purpose of reflection is to learn from experiences. Struggles, dilemmas, and uncertainties are some valuable experiences for reflection. Usually, reflection leads to a certain level of discomfort at the beginning, and it ends with learning, deeper insights and a better understanding of past experiences. In other words, students will develop better self-knowledge after a reflection process by self-assessment of themselves. Desjarlais and Smith (2013) stressed that both self-assessment and reflection are some private actions. It should be carried out in an uninterrupted period at a place free of distractions.

As discussed in the literature above, the main drawback of the traditional instructional methods is that students may, under the open settings in the classroom, create a self-presentation of being an ethical cybercitizen. They may not disclose their genuine attitude for the public censure, and the teaching effectiveness may not be satisfactory enough. In this study, the researcher attempted to enhance students' self-knowledge and self-awareness of their attitude on cyberethics and their online behaviours using a pressure-free self-assessment instructional method. By removing the incentive of creating a self-presentation in the process of self-assessment, it is believed that they would have a more in-depth and genuine reflection. The instructional method could, thereby, improve their attitude on cyberethics.

\section{METHODOLOGY}

\section{RESEARCH DESIGN}

The study was carried out in a secondary school in Hong Kong. The researcher adopted a convenient sampling approach. A total of 28 students at secondary three level of age about 14 participated in this 
study. Students were required to take an information technology course in their formal curriculum. The instructional method designed by the researcher was implemented in the course during the teaching of computer ethics. After explained the research aims, formal consent from the school was obtained to carry out the study.

The overall design of the instructional method is illustrated in Figure 2. The instructional method involved two phases. The purpose of the first phase was to enable students to obtain background knowledge of cyberethics. The second phase, with a pressure-free self-assessment element, aimed to enhance students' self-knowledge and self-awareness on cyberethics. In the first phase, a lesson on cyberethics was given to the students. In addition to the delivery of a lecture, the students were instructed to use software to learn related knowledge. The design of the software was based on the adolescents' cyberethics framework (Figure 1). For each dimension of the framework, the software provides its definition, relevant issues and ordinances, and the ways to satisfy online ethical problems. The software also includes an interactive exercise with immediate feedback. After the lesson, a knowledge test was given to the students to investigate whether they had obtained relevant knowledge. The test was a short quiz with questions addressed the four dimensions of the adolescents' cyberethics framework (Figure 1). The questions were in the format of "Fill in the Blanks", "True or False" and "Multiple Choice". All items attempted to examine students' understanding of fundamental concepts of cyberethics. Full mark of the test was 100. After the first phase, it was expected that students could obtain sufficient knowledge on cyberethics and were able to make an informed judgment in the self-assessment exercise.

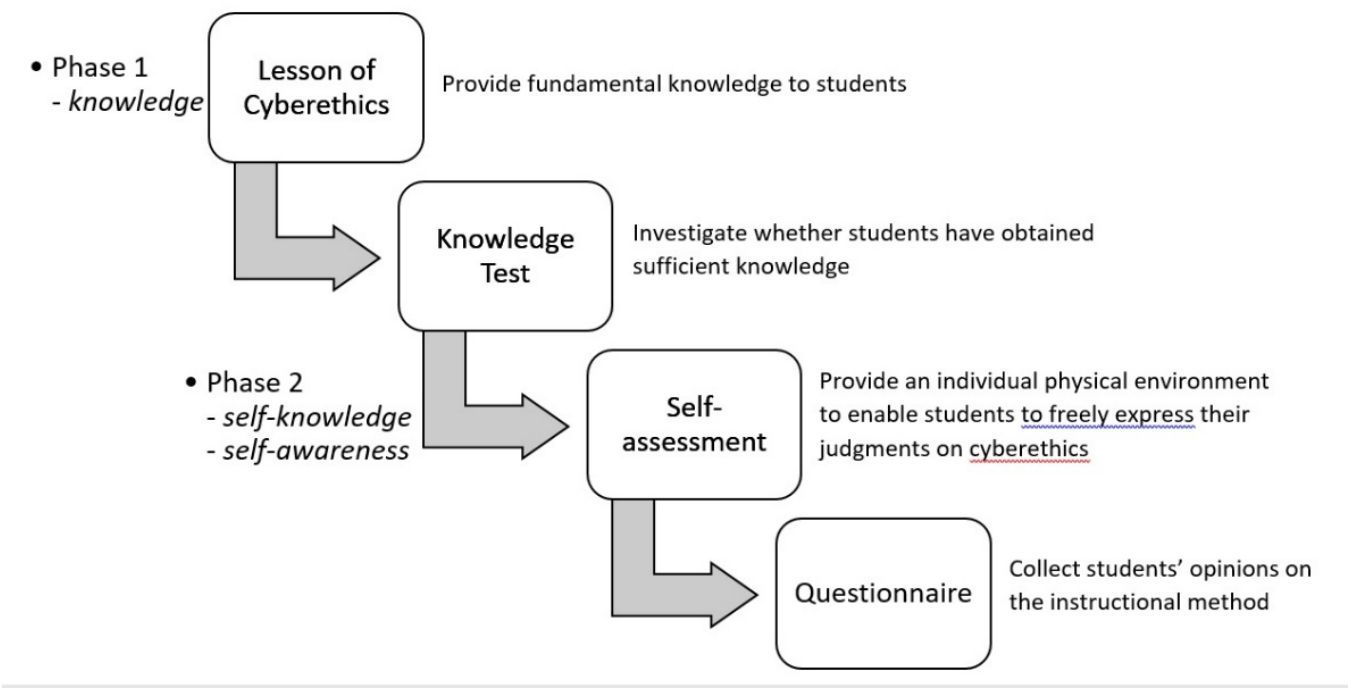

Figure 2: Overall design of the instructional method

In the second phase, each student was instructed to carry out a self-assessment exercise on cyberethics using a computer in an individual physical environment. The self-assessment exercise was implemented in an online platform. All questions in the self-assessment exercise involved ethical scenarios in four dimensions of the adolescents' cyberethics framework (Figure 1). The questions were adapted from that used in the studies by Chen (2011) and Masrom's team (2013). All questions were in multiple-choice format and were arranged in random order. Student's responses were used to evaluate a profile regarding his or her attitudes on cyberethics. At the end of the self-assessment exercise, a report was generated to enable the student to understand his or her attitudes on cyberethics. An example of the report is shown in Figure 3. The student in this example demonstrated a good attitude to respect the intellectual property $(90 \%)$ and satisfactory attitude on information security $(70 \%)$. However, the student showed weak attitudes on netiquette (60\%) and privacy (50\%). A short description was also provided to highlight his/her good knowledge and attitude on protecting intellec- 
tual property. This report served as a piece of critical feedback after self-assessment. Students obtaining this report could have better self-knowledge regarding their attitudes on cyberethics. As discussed in Literature Review, self-knowledge could bring positive effects on an individual's future behaviours. Students, with a good understanding of themselves, will be more self-aware and act in a more normative manner. It is expected that their attitude on cyberethics and online behaviours would then be improved.

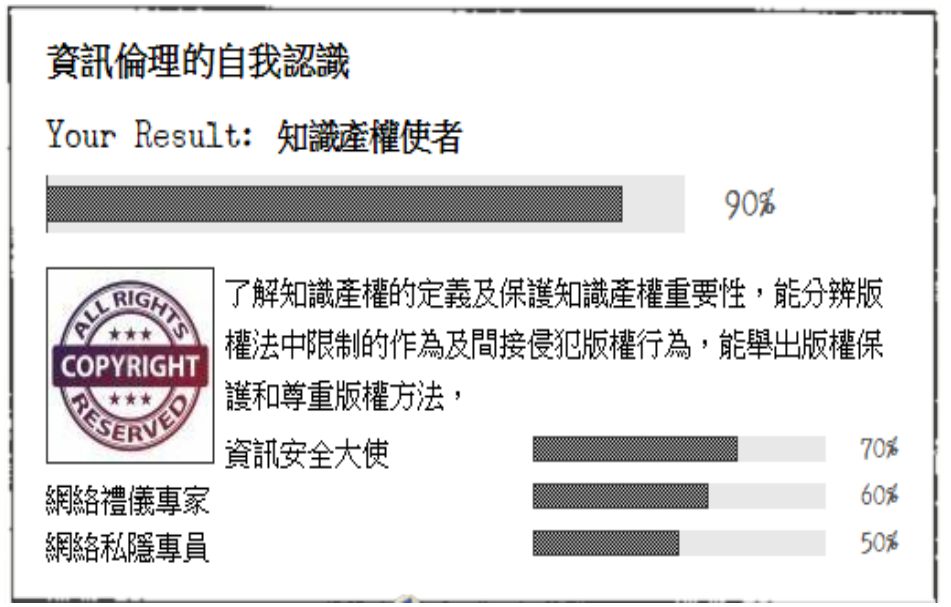

Figure 3: An example of attitude profile of adolescents' cyberethics

To create a pressure-free environment, the researcher informed the students before the start of the exercise that the self-assessment exercise aimed to enhance the self-knowledge regarding their attitudes on cyberethics. They were assured that their responses in the self-assessment exercise would not incur any adverse consequence and subsequent analyses only aimed to improve teaching effectiveness. They were encouraged to freely respond to all questions based on their personal ethical standards. They were also told that the self-assessment exercise was solely for personal reflection, and they were not required to fulfil teachers' or peers' expectations. This practice created a pressurefree environment with teachers' expectation and peers' influence removed. It was anticipated that they would not deliberately express a self-presentation. Students could thereby complete the self-assessment exercise based on their ethical standards, and this arrangement guaranteed a reliable result.

After the self-assessment, students were invited to fill out a questionnaire concerning their views on the instructional method. The questionnaire was adapted from the "Student Evaluation of Teaching Questionnaire" used in The Education University of Hong Kong (EdUHK, 2020). Similar wordings, structure and response scale were adopted. The "Student Evaluation of Teaching Questionnaire" has been used for over ten years in the University in all offered courses. It has been verified and obtained a high level of reliability and validity. In the questionnaire of this study, four questions were included in asking about whether the instructional method could enhance their understanding of information security, privacy, intellectual property and netiquette, respectively. Another four items listed below were included in asking about whether the self-assessment exercise could enhance their selfknowledge and self-awareness on cyberethics.

- The self-assessment exercise effectively enabled me to reflect on my attitudes on cyberethics.

- The report generated from the self-assessment exercise allowed me to understand my attitudes on cyberethics.

- Compared with commonly used instructional methods such as open discussion and debate, a self-assessment exercise is more effective for me to reflect on my attitudes on cyberethics.

- After the self-assessment exercise, I will be more aware of cyberethics in future online activities. 
Students were invited to express their views by choosing "Strongly Agree", "Agree", "Disagree" and "Strongly Disagree".

\section{RESULTS}

As the participants were adolescents whose responses might be challenged due to their immaturity, multiple data collection methods were used to serve the purpose of data triangulation. Three sets of data were collected by the knowledge test, the questionnaire, and the self-assessment exercise, respectively, in this study. Since the related instructional method was implemented in the class, all participants were willing to respond to all three instruments. The data were analysed using SPSS. Results are elaborated in the following sections.

\section{RESULTS OF KNOWLEDGE TEST}

The mean score of the knowledge test was 80.21 , with a standard deviation of 7.25 . The minimum and maximum scores were 68 and 92 , respectively. The results suggested that the students obtained sufficient knowledge of cyberethics. It was believed that they were able to make an informed judgment in the self-assessment exercise.

\section{RESULTS OF QUESTIONNAIRE}

The results of the questionnaire are listed in Table 1 and Table 2. When asking whether the instructional method enhanced their knowledge on different dimensions of cyberethics, the mean values of responses ranged from 3.25 to 3.46 ( 1 - strongly disagree, $4-$ strongly agree). A one-sample t-test was executed on mid-value of the range (2.5). Significant results were obtained in all questions with a $95 \%$ confidence interval. It suggested that the students considered the instructional method was able to enhance their understanding in all four dimensions of the adolescents' cyberethics framework (Figure 1). For those questions asking whether the self-assessment exercise enhanced their selfknowledge and self-awareness on cyberethics, the mean values ranged from 3.21 to 3.43 (1 - strongly disagree, 4 - strongly agree). A one-sample t-test was also executed on mid-value of the range (2.5). Significant results were obtained in all questions, with a 95\% confidence interval. It suggested that the self-assessment exercise could effectively enable students to reflect on their attitudes on cyberethics. Students also considered that the report generated from the self-assessment exercise allowed them to understand their attitudes on cyberethics. In addition, they found the self-assessment exercise was more effective for them to reflect on their attitudes on cyberethics when compared with commonly used instructional methods such as open discussion and debate. More importantly, they expressed that they will be more aware of cyberethics in their future online activities.

Table 1: One-sample t-test descriptive statistics

\begin{tabular}{|l|c|c|c|c|}
\hline & $\mathbf{N}$ & $\mathbf{M e a n}$ & Std. Deviation & Std. Error Mean \\
\hline Enhanced Information Security Knowledge & 28 & 3.321 & .4756 & .0899 \\
\hline Enhanced Privacy Knowledge & 28 & 3.464 & .5079 & .0960 \\
\hline Enhanced Intellectual Property Knowledge & 28 & 3.429 & .5040 & .0952 \\
\hline Enhanced Netiquette Knowledge & 28 & 3.250 & .7005 & .1324 \\
\hline Self-assessment Enabled Reflection & 28 & 3.214 & .5681 & .1074 \\
\hline Self-assessment Report Enhanced Self-knowledge & 28 & 3.286 & .6587 & .1245 \\
\hline Self-assessment was More Effective for Reflection & 28 & 3.429 & .5727 & .1082 \\
\hline Self-assessment Enhanced Self-awareness & 28 & 3.357 & .5587 & .1056 \\
\hline
\end{tabular}

(1 - Strongly disagree, 4 - Strongly agree) 
Table 2: One-sample t-test on mid-value (2.5)

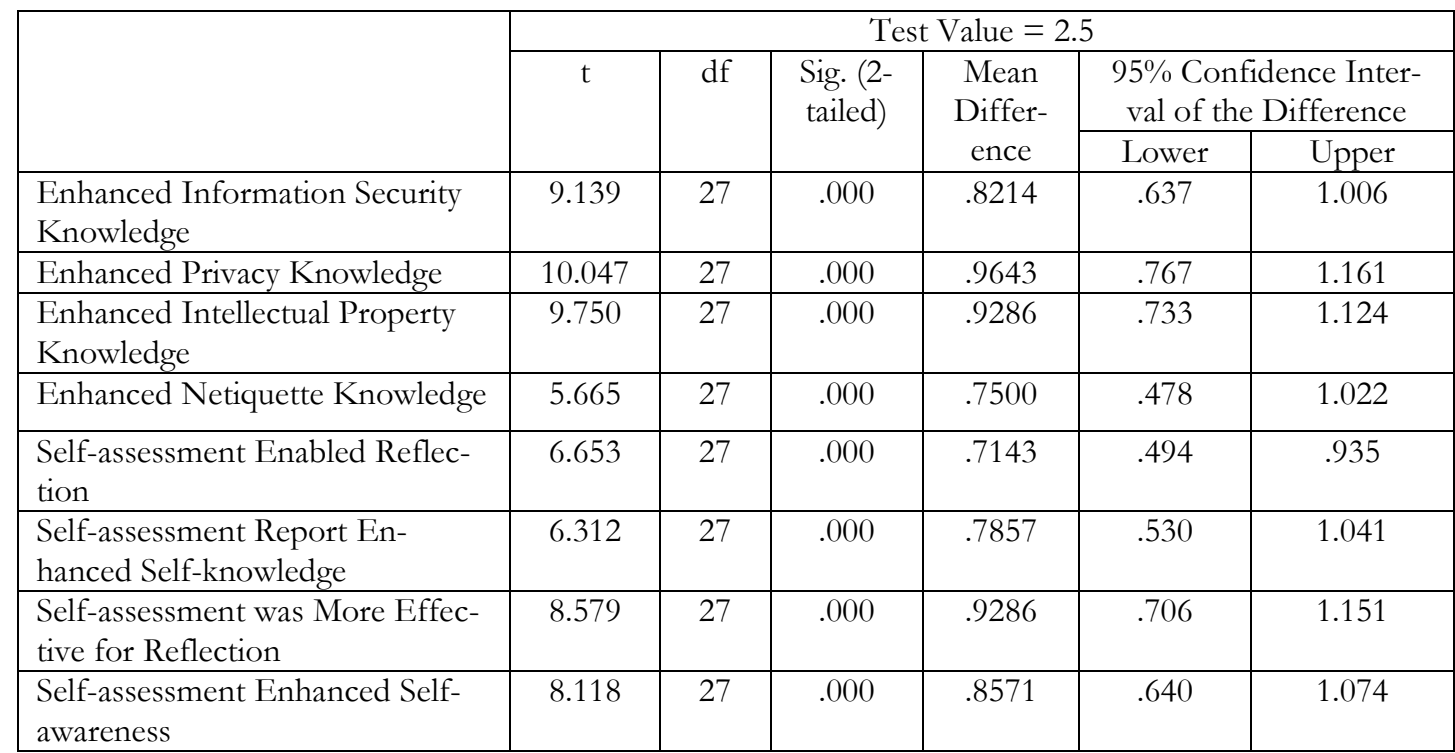

\section{RESULTS OF SELF-ASSESSMENT EXERCISE}

Results of students' responses in the self-assessment exercise are shown in Table 3 . The mean values of students' response in 4 different dimensions of adolescents' cyberethics framework ranged from 60.8 to 78.2 . This result suggested that the students, in general, had satisfactory attitudes on cyberethics. On the other hand, it is worth noting that the values of standard deviation in 4 dimensions were considerably high and the minimum values ranged from 0 to 30 . It reflected that some students held unsatisfactory attitudes on cyberethics, and they were willing to express their views in the self-assessment exercise. It provided supporting evidence that students, under the pressure-free individual physical environment, were not required to express a self-presentation deliberately and they were willing to express their attitudes on ethical cases truly.

Table 3: Descriptive statistics of results of the self-assessment exercise

\begin{tabular}{|l|c|c|c|c|c|}
\hline \multicolumn{2}{|l|}{} & Information Security & Privacy & Intellectual Property & Netiquette \\
\hline \multirow{2}{*}{$\mathrm{N}$} & Valid & 28 & 28 & 28 & 28 \\
\cline { 2 - 5 } & Missing & 0 & 0 & 0 & 0 \\
\hline Mean & 78.000 & 60.786 & 69.857 & 78.179 \\
\hline Median & 83.500 & 60.000 & 78.500 & 80.000 \\
\hline Mode & 100.0 & 60.0 & 90.0 & 100.0 \\
\hline Std. Deviation & 23.3809 & 16.0031 & 23.7514 & 18.6091 \\
\hline Minimum & .0 & 20.0 & 11.0 & 30.0 \\
\hline Maximum & 100.0 & 100.0 & 100.0 & 100.0 \\
\hline
\end{tabular}

\section{DISCUSSION}

For those commonly used instructional methods to nurture ethics, such as discussion, debate and role-playing, open dialogue between learners was considered as a critical element in the process (Dow et al., 2015; Hur et al., 2009; Lin, 2016; Liu \& Yang, 2012; Tatsumi et al., 2013). Students, in the process of critical discussions, were assumed to initiate a reflection on their own values or attitudes on ethical issues. Students were thereby expected to change their attitudes and behaviours. However, the question is to what extent the students would genuinely express their views and reflect on their attitudes in an open setting with the presence of teachers and peers. Teachers are in a position with higher power and peers observation provokes a certain level of social pressure. The open setting in previous studies inevitably increased the possibility that students would deliberately present a self- 
presentation for obtaining favourable evaluation especially they were in adolescence stage (Schlenker, 1975; Taylor et al., 2006). This study applied an instructional method with a self-assessment element to enable the students to address their personal attitudes (Amulya, 2004; Desjarlais \& Smith, 2013). It aimed to enhance their self-knowledge and self-awareness on cyberethics using a method with a core element of a self-assessment exercise. A significant difference of this method was that it did not rely on the dialogue between learners. Statistically significant results (Table $1 \&$ Table 2) were obtained from the questionnaires that the students considered the instructional method effectively enabled self-reflection and enhanced self-knowledge on their attitudes on cyberethics. The students also expressed that the method in this study was more effective for self-reflection compared with commonly used methods. It further confirmed the arguments that self-assessment promotes self-reflection (Desjarlais \& Smith, 2013) and self-reflection leads to personal growth (Amulya, 2004; Leise, 2007).

The students in this study expressed that they will be more aware of cyberethics in future online activities after developed better self-knowledge. This result strengthened Markus's (1983) argument that self-knowledge plays a significant role in determining the behaviour of an individual. Besides, the result also supported the findings in previous studies (Diener, 1976; Duval \& Wicklund, 1972) that a self-aware person will be more likely to act in a normative manner and self-awareness help inhibit unrestrained, impulsive behaviour.

In this study, the provision of background knowledge on cyberethics and the pressure-free environment were critical factors to enhance the effectiveness of the self-assessment exercise and the instructional method as a whole. Students were required to obtain sufficient background knowledge on cyberethics to make an informed judgment on ethical issues. On the other hand, a lot of measures were deliberately inserted in the process by the researcher to create a pressure-free environment. This issue has been highlighted by Desjarlais and Smith (2013) that self-assessment and reflection should be carried out in an uninterrupted period at a place free of distractions. It includes to arrange students in an individual physical environment and provide a clear announcement to students at the beginning of the self-assessment exercise with the followings:

- explain that the aim of the self-assessment exercise is for self-reflection on cyberethics

- emphasize that no adverse consequence will incur

- stress that students are not required to fulfil teachers' or peers' expectations

- encourage students to respond to questions based on their personal ethical standards freely

All these arrangements aimed to remove possible pressure generated from the presence of teachers and peers. Students should have no incentive to present a self-presentation. Results in the self-assessment exercise showed that students were willing to express their unsatisfactory attitudes on cyberethics in this pressure-free environment. Moreover, the private, individual and pressure-free physical environment created in this study for making decisions in the self-assessment exercise was similar to the physical environment when students go online individually to deal with cyberethics issues. Their decisions were solely based on their attitude on cyberethics without influenced by others. This setting further enhanced the effectiveness of the instructional method and the reliability of the results.

In consideration of research ethic, this study did not further arrange students in an environment that provides opportunities for them to infringe cyberethics. It is unethical to create an environment for participants to elicit unethical behaviours, especially that the participants in this study were adolescents who should be protected. This issue could be regarded as the limitation of this study. 


\section{CONCLUSION}

This study contributed to the area of ethics education in both theoretical and practical aspects. In the theoretical perspective, the researcher suggested an adolescents' cyberethics framework with dimensions of information security, privacy, intellectual property and netiquette. To nurture adolescents' cyberethics, the researcher emphasized the importance of including theories of self-presentation, selfknowledge and self-awareness in the area of social psychology into cyberethics education. Besides, the application of self-assessment to trigger reflection for enhancing self-knowledge is critical in cyberethics education. Future research may further investigate how cognitive, psychological, social and emotional factors affect adolescents in cyber-ethical decision making, and proposal effective methods for adolescents' cyberethics education.

In a practical point of view, this study highlighted the inadequacy of commonly used instructional method of nurturing adolescents' cyberethics that applies an open classroom setting with the presence of teachers and peers. The researcher suggested the inclusion of a pressure-free self-assessment exercise with underpinning theories of self-presentation, self-knowledge and self-awareness to remedy the adequacy. This study also highlighted the required measures of generating a pressure-free environment to enhance the effectiveness of the self-assessment exercise. As suggested by the favourable results in this study, education practitioners are recommended to include a pressure-free self-assessment exercise together with commonly used instructional methods, such as case-based discussion, debate and role-playing, in their future practices of ethics education.

\section{REFERENCES}

Amulya, J. (2004). What is reflective practice? Centre for Reflective Community Practice at the Massachusetts Institute of Technology. http://www.itslifejimbutnotasweknowit.org.uk/ files/whatisreflectivepractice.pdf

Ang, R. P. (2015). Adolescent cyberbullying: A review of characteristics, prevention and intervention strategies. Aggression and Violent Behaviour, 25(Part A), 35-42. https://doi.org/10.1016/j.avb.2015.07.011

Ang, R. P., Huan, V. S., \& Florell, D. (2014). Understanding the relationship between proactive and reactive aggression, and cyberbullying across United States and Singapore adolescent samples. Journal of Interpersonal Violence, 29(2), 237-254. https://doi.org/10.1177/0886260513505149

Baumeister, R. F., \& Bushman, B. J. (2016). Social psychology and human nature (4th ed.). Cengage Learning.

Boud, D., \& Falchikov, N. (1989). Quantitative studies of self-assessment in higher education: A critical analysis of findings. Higher Education, 18(5), 529-549. https://doi.org/10.1007/BF00138746

Capurro, R. (2005). Information ethics. Computer Society of India (CSI).

Cauffman, E., \& Steinberg, L. (2000). (Im)maturity of judgment in adolescence: Why adolescents may be less culpable than adults. Behavioural Science \& the Law, 18(6), 741-760. https://doi.org/10.1002/bsl.416

Census and Statistics Department. (2020). Thematic household survey report No. 69. Hong Kong Special Administrative Region (HKSAR). https://www.statistics.gov.hk/pub/B11302692020XXXXB0100.pdf

Chen, Y. C. (2011). A study on the information ethics behaviour of elementary school student: A case of an elementary school in new Taipei City. Chung Hua University. http://chur.chu.edu.tw/bitstream/987654321/1569/1/GM099100100.pdf

Clement, J. (2019, July 31). Average duration of daily internet usage worldwide as of 1 st quarter 2019, by age group and device. Statista. https://www.statista.com/statistics/416850/average-duration-of-internet-use-age-device/

Desjarlais, M., \& Smith, P. (2011). A comparative analysis of reflection and self-assessment. International Journal of Process Education, 3(1), 3-18. http://www.ijpe.online/2011/reflectionh.pdf

Dhir, A., Chen, S., \& Nieminen, M. (2016). Psychometric validation of the compulsive internet use scale: Relationship with adolescents' demographics, ICT accessibility, and problematic ICT use. Social Science Computer Review, 34(2), 197-214. https://doi.org/10.1177/0894439315572575 
A Self-assessment Approach to Adolescents' Cyberethics Education

Diener, E. (1976). Effects of self-awareness on antinormative behaviour. Journal of Research in Personality, 10(1), 107-111. https://doi.org/10.1016/0092-6566(76)90088-X

Dow, M. J., Boettcher, C. A., Diego, J. F., Karch, M. E., Todd-Diaz, A., \& Woods, K. M. (2015). Case-based learning as pedagogy for teaching information ethics based on the Dervin Sense-making Methodology. Journal of Education for Library and Information Science, 56(2), 141-157. https://doi.org/10.3138/jelis.56.2.141

Duval, S., \& Wicklund, R. A. (1972). A theory of objective self-awareness. Academic Press. https://psycnet.apa.org/record/1973-26817-000

EdUHK. (2020). Student evaluation of teaching and institutional research on graduates. The Education University of Hong Kong: https://lt.eduhk.hk/teaching/set-irg/

Gilmore, K. J., \& Meersand, P. (2015). The little book of cbild and adolescent development. Oxford University Press. https://doi.org/10.1093/med/9780199899227.001.0001

Goffman, E. (2010). Relations in public: Microstudies of the public order. Transaction Press.

Gunter, W. D., Higgins, G. E., \& Gealt, R. E. (2010). Pirating youth: Examining the correlates of digital music piracy among adolescents. International Journal of Cyber Criminology, 4(1), 657-671. http://www.cybercrimejournal.com/whitneyetal2010ijcc.pdf

Halpern-Felsher, B. (2012). Adolescent decision making. In F. E. Stickle (Ed.), Adolescent psychology (pp. 11-16). McGraw-Hill.

Harncharnchai, A., \& Inplao, K. (2015). Information ethics and behaviours of upper secondary students regarding the use of computers and the Internet. Journal of Information Ethics, 24(1), 98-116.

The Hong Kong Institute of Education. (2007, April 17). Phase (I) study on evaluating the effectiveness of the Empowering Learning and Teaching with Information Technology' Strategy (2004/2007). Hong Kong: Education Bureau (EDB). https://www.edb.gov.hk/attachment/en/edu-system/primary-secondary/applicable-to-primarysecondary $/$ it-in-edu/phase $\% 20$ (i) $\% 20$ study $\% 20-\% 20$ whole $\% 20$ final $\% 20$ report.pdf

Hu, Q., Xu, Z., \& Yayla, A. A. (2013). Why college students commit computer hacks: Insights from a cross culture analysis. Proceedings of the Pacific Asia Conference on Information Systems (PACIS). Jeju Island, Korea: Association for Information Systems (AIS). http://aisel.aisnet.org/pacis2013/104

Hur, J. H., Kim, K. Y., Song, J. B., \& Lee, T. W. (2009). The narrative approach to teach information and communication ethics education in elementary school. Proceedings of the $17^{\text {th }}$ International Conference on Computers in Education, Volume 6 (pp. 960-964). Hong Kong: Asia-Pacific Society for Computers in Education.

Jones, S. C. (1973). Self- and interpersonal evaluations: Esteem theories versus consistency theories. Psychological Bulletin, 79(3), 185-199. https://doi.org/10.1037/h0033957

Juvonen, J., \& Murdock, T. B. (1995). Grade-level differences in the social value of effort: Implications for selfpresentation tactics of early adolescents. Cbild Development, 66(6), 1694-1705. https://doi.org/10.2307/1131904

Kohlberg, L., \& Hersh, R. H. (1977). Moral development: A review of the theory. Theory into Practice, 16(2), 5359. https://doi.org/10.1080/00405847709542675

Kowalski, R. M., \& Limber, S. P. (2007). Electronic bullying among middle school students. Journal of Adolescent Health, 41(6), S22-S30. https://doi.org/10.1016/j.jadohealth.2007.08.017

Kumazaki, A., Suzuki, K., Katsura, R., Sakamoto, A., \& Kashibuchi, M. (2011). The effects of netiquette and ICT skills on school-bullying and cyber-bullying: The two-wave panel study of Japanese elementary, secondary, and high school students. Procedia - Social and Behavioural Sciences, 29, 735-741. https://doi.org/10.1016/j.sbspro.2011.11.299

Layton, T. P. (2016). Information security: Design, implementation, measurement, and compliance. Auerbach Publications. https://doi.org/10.1201/9781420013412

Lazuras, L., Pyzalski, J., Barkoukis, V., \& Tsorbatzoudis, H. (2012). Empathy and moral disengagement in adolescent cyberbullying: Implications for educational intervention and pedagogical practice. Studia Edukacyjne, 23, 57-69. https://repozytorium.amu.edu.pl/bitstream/10593/5894/1/studia eduk_23 s 57-70.pdf 
Leise, C. (2007). Learning processes through the use of methodologies. In S. W. Beyerlein, C. Holmes, \& D. K. Apple (Eds.), Faculty guidebook: A comprehensive tool for improving faculty performance (4th ed.), (pp. 217-220). Pacific Crest. http://pcrest.com/L2LTI/recovery/WGU/june/6/LP method.pdf

Lin, C. S. (2016). Educating students' privacy decision making through information ethics curriculum. Creative Education, 7(1), 171-179. https://doi.org/10.4236/ce.2016.71017

Liu, C. J., \& Yang, S. C. (2012). Applying the Practical Inquiry Model to investigate the quality of students' online discourse in an information ethics course based on Bloom's teaching goal and Bird's 3C model. Computers \& Education, 59(2), 466-480. https://doi.org/10.1016/i.compedu.2012.01.018

Markus, H. (1983). Self-knowledge: An expanded view. Journal of Personality, 51(3), 543-565. https://doi.org/10.1111/j.1467-6494.1983.tb00344.x

Mason, R. O. (1986). Four ethical issues of the information age. MIS Quarterly, 10(1), 5-12. https://doi.org/10.2307/248873

Masrom, M., Mahmood, N. H., \& Zainon, O. (2013). Cyberethics and internet behaviour of Malaysian primary education students. Journal of Emerging Trends in Educational Research and Policy Studies, 4(1), 105-111. https://hdl.handle.net/10520/EJC132402

McBride, N. K. (2014). ACTIVE ethics: An information systems ethics for the internet age. Journal of Information, Communication and Ethics in Society, 12(1), 21-43. https://doi.org/10.1108/JICES-06-2013-0017

Ming, T. M., Jabar, M. A., Sidi, F., \& Wei, K. T. (2015). A systematic literature review of computer ethics issues. Journal of Theoretical and Applied Information Technology, 78(3), 360-372. http://www.jatit.org/volumes/Vol78No3/4Vol78No3.pdf

Ncube, L. S., \& Dube, L. (2016). Cyberbullying a desecration of information ethics: Perceptions of post high school youth in a rural community. Journal of Information, Communication and Ethics in Society, 14(4), 313-322. https://doi.org/10.1108/JICES-04-2016-0009

$\mathrm{Ng}$, W. S. (2020). Enhancing the quality of educational website design through assessment for learning strategies. In M. Khosrow-Pour (Ed.), Learning and performance assessment: Concepts, methodologies, tools, and applications (pp. 1106-1133). IGI Global. https:// doi.org/10.4018/978-1-7998-0420-8.ch052

Onyancha, O. B. (2015). An informetrics view of the relationship between internet ethics, computer ethics and cyberethics. Library Hi Tech, 33(3), 387-408. https://doi.org/10.1108/LHT-04-2015-0033

The Organisation for Economic Co-operation and Development (OECD). (2014). PIS A 2012 results: Students and money: Financial literacy skills for the $21^{15 t}$ Century (volume VI). Programme for International Student Assessment (PISA). OECD Publishing. http://www.oecd.org/pisa/keyfindings/pisa-2012-results-volume-vi.pdf

Park, S., Na, E. Y., \& Kim, E. M. (2014). The relationship between online activities, netiquette and cyberbullying. Children and Youth Services Review, 42, 74-81. https://doi.org/10.1016/j.childyouth.2014.04.002

Peltier, T. R. (2016). Information security policies, procedures, and standards: Guidelines for effective information security management. Auerbach Publications. https://doi.org/10.1201/9780849390326

Raskauskas, J., \& Stoltz, A. D. (2007). Involvement in traditional and electronic bullying among adolescents. Developmental Psychology, 43(3), 564-575. https://doi.org/10.1037/0012-1649.43.3.564

Schlenker, B. R. (1975). Self-presentation: Managing the impression of consistency when reality interferes with self-enhancement. Journal of Personality and Social Psychology, 32(6), 1030-1037. https://doi.org/10.1037/0022-3514.32.6.1030

Sharma, M., Mittal, S., \& Verma, A. (2015). Cyber ethics in security application in the modern era of Internet. IITM Journal of Management and IT, 6(1), 140-143. https://iitmjp.ac.in/wp-content/uploads/2017/06/ITConference-2015.pdf\#page $=140$

Shea, V. (1994). Netiquette. Albion Books. http://www.albion.com/netiquette/book/index.html

Shiri, A. (2016). Exploring information ethics: A metadata analytics approach. Journal of Information Ethics, 25(1), 17-37. https://dataethics.site/Library/LibContentAcademic/Exploring Information Ethics .pdf 
Silva, C. S., Martins, A. C., \& Calheiros, M. M. (2016). Development and psychometric properties of the selfrepresentation questionnaire for adolescents (SRQA). Journal of Child and Family Studies, 25(9), 2718-2732. https://doi.org/10.1007/s10826-016-0438-1

Spinello, R. A., \& Tavani, H. T. (2004). Readings in cyberethics. Jones and Bartlett Publishers.

Steinberg, L. (2007). Rick taking in adolescence: New perspectives from brain and behavioural science. Current Directions in Psychological Science, 16(2), 55-59. https://doi.org/10.1111/j.1467-8721.2007.00475.x

Tatsumi, T., Nakano, Y., Kusumoto, N., Maeno, J., \& Harada, Y. (2013). To bear the unbearable: College-level information ethics education incorporating discussions of ethical dilemmas. Proceedings of the Thirteenth International Conference on the possibilities of ethical ICT (pp. 450-456). Kolding: University of Southern Denmark.

Taylor, S. E., Peplau, L. A., \& Sears, D. O. (2006). Social psychology. Pearson.

The United Nations Children's Fund (UNICEF) (2020). Adolescent development and participation: Investing in adolescents builds strong economies, inclusive communities and vibrant societies. UNICEF for Every Child. https://www.unicef.org/adolescence

Varlan, S. E., \& Tomozei, C. (2018). Categories of ethical issues in the use of information and communication technologies. Journal of Innovation in Psychology, Education and Didactics, 22(2), 155-166. http://www.jiped.ub.ro/wp-content/uploads/2018/11/JIPED 2222018 2.pdf

Vaz, L., \& Kanekar, S. (1992). Gender differences in likelihood estimates and recommendations regarding antinormative behaviour in different ethical contexts. Journal of Applied Social Psychology, 22(21), 1688-1701. https://doi.org/10.1111/j.1559-1816.1992.tb00970.x

Von Solms, R., \& Van Niekerk, J. (2013). From information security to cyber security. Computers \& Security, 38, 97-102. https://doi.org/10.1016/i.cose.2013.04.004

Whittier, D. B. (2013). Cyberethics: Envisioning character education in cyberspace. Peabody Journal of Education, 88(2), 225-242. https://doi.org/10.1080/0161956X.2013.775882

World Health Organization (WHO) (2020). Adolescence: A period needing special attention. https://apps.who.int/adolescent/second-decade/section $2 /$ page1/recognizing-adolescence.html

Woodward, B., Martin, N., \& Imboden, T. (2010). Expansion and validation of the PAPA Framework. Proceedings of the 2010 Conference on Information Systems Education (ISECON) (pp. 1-7). Nashville Tennessee, USA: Education Special Interest Group (EDSIG). https://files.eric.ed.gov/fulltext/EJ1145453.pdf

\section{BIOGRAPHY}

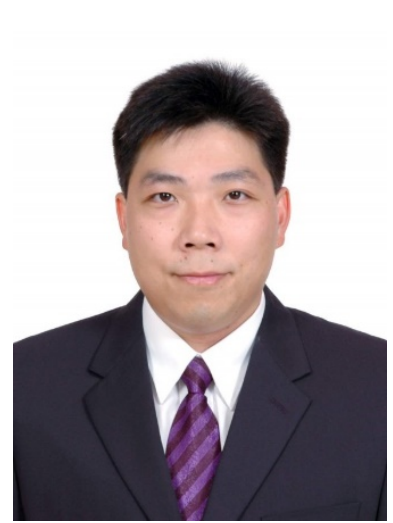

Wing Shui Ng is a Research Assistant Professor in The Open University of Hong Kong. He received his Doctor of Education from the University of Bristol. He has extensive involvement in computer education in Hong Kong. With continuous engagement in the academic field, he has published a number of scholarly articles, including journal papers, conference papers, book chapters, and an edited book, in the areas of Educational Assessment, Information Technology in Education, and STEM Education. He also serves as an Associate Editor-in-Chief of The International Journal of Doctoral Studies (IJDS), a Reviewer of international journals, conferences and academic books, and a Speaker as well as a Committee Member of international conferences. 